\title{
Health Care Insurance and Moral Hazard
}

DOI: https://doi.org/10.47175/rissj.v2i3.268

\section{| Hong $\mathrm{MaO}^{1}$ | Jin Wang |}

\author{
${ }^{1}$ Shanghai Second \\ Polytechnic University \\ hmaoi@vip.126.com
}

\begin{abstract}
In this article, we discuss how moral hazard affects health care insurance, the social benefit and the harmfulness of moral hazard in health care insurance. We also discuss the relationship between copayment rate and decease risks and indicate that it is necessary to reduce copayment ratio for serious decease in social health care insurance in order to generate social gain. Finally, we carry out sensitivity analysis to illustrate the effect of the change of important parameters on optimal copayment rate. KEYWORDS

health care; copayment rate; moral hazard; social benefit; the insured's benefit
\end{abstract}

\section{INTRODUCTION}

Nyman (1999) discussed the question: Why do people purchase health care insurance? He suggests a key factor: Health care insurance is demanded because it represents a mechanism for gaining access to health care that would otherwise be unaffordable.

On moral hazard, there are generally two kinds of definitions. One (in economic theory) defines moral hazard as a situation where a party will tend to take risks because the cost will not be felt by the party. Another defines moral hazard as the additional insurance purchased which exceeds the real value of the exposure insured. Nyman (2004) refers the moral hazard in the case of health care insurance as the additional health care that is purchased when persons become insured.

In conventional insurance theory, all of moral hazard is generally thought of as a bad thing. Insurance companies undertake significant efforts to decrease, or even to avoid, moral hazard. They make special provisions in insurance contracts to limit the moral hazard of the insured. For example: deductibles, copayment and so on. However, insurance and moral hazard are really a couple of twins. Where this is insurance, there is moral hazard. It is impossible and also it is unnecessary to avoid moral hazard completely. And Mao, et al (2018) show that moral hazard in some conditions is desirable to the insured and to the society as well.

Nyman (2004) presents a new theory on moral hazard. He suggests that much of moral hazard is actually efficient. He especially emphasizes that when the care that was deemed to be welfare-decreasing is reclassified as welfare-increasing, health insurance becomes much more valuable to the consumers. He illustrates that the moral hazard in health insurance sometimes can benefit to the society. The reason is that when the insured buys additional health care insurance he/she can get higher claim payment in the case that claim event occurs. Therefore, he/she can receive better health care, because he/she can afford higher cost of higher level of health care. It is extremely necessary, especially, when the insured experiences a serious illness ${ }^{1}$. This, in turn, is very likely to bring about improvement of society's welfare.

\footnotetext{
${ }^{1}$ Pauly (1983) point out that it is nevertheless true that the relevant theory, empirical evidence, and policy analysis for moral hazard in the case of serious illness has not been developed. This is one of the most serious omissions in the current literature.
} 
Copayment policy can actually be an inefficient restriction of moral hazard. But when moral hazard generates welfare gain, it should be left in place, or even encouraged. For example, in health care insurance, As Nyman (2004) points out that if the insured has a serious illness, care might also be associated with a great deal of pain and suffering anyway, and it may make no sense to require copayments if this discourages already difficult treatment.

What is important is that health care policy, or government regulations, should encourage risk taking and moral hazard, which is beneficial to the society and at the same time limits those which are detrimental to the society.

Rational pricing of the moral hazard is one of effective ways to decrease the moral hazard which is detrimental to the society. Hence, market design and government regulation should encourage rational insurance pricing. Subsidizing insurance premiums is thought of as a way to make the consumer better off but also it is very likely to cause excessive moral hazard. Nyman (2004) points out that the subsidies that encourage consumers to purchase insurance voluntarily, or a national health care insurance program for the entire U.S. population would improve society's welfare. However, Pauly (1983) points out that subsidizing health care insurance through the tax system is likely to bring about detrimental moral hazard. Although subsidies are paid by the government, if the benefit obtained by the insured from the subsidies is larger than the cost of subsidies, this may result in improvement of society's welfare. Otherwise, subsidies can and do cause negative externality.

Shahar and Logue (2012) explore the potential value of insurance as a substitute for government regulation of safety. Insurance companies can take measures to decrease the moral hazard, which is harmful to insurers and to the society as well. For example, copayment, deductibles, upper limits of insurance benefit, premium adjustment to encourage those taking effective prevention measures and punish those that create moral hazard which is detrimental to insured and to the society as well. Other natural mechanisms are: Exclusions of certain risks, or advice on risk management procedures that insurance companies provide. Let us also note that items not directly tied to price or contract structure can be used: home insurance companies advice customers who live in hurricane prone areas about how their homes should be built to withstand hurricanes, at least to some degree.

It should be noted also that for moral hazard that is not beneficial to the insurance company, but desirable to the insured and to the society, the encouragement by government is potentially important. For example, for serious illness insurance, government can provide social health care insurance with lump sum payment when the claim event occurs, or with low cost sharing ratio.

Health care insurance is often thought of as a form of insurance that is most likely to produce moral hazard. Insurance companies have serious concerns about practical operations of health care insurance. However, moral hazard of the insured, which is usually thought of as harmful to the insurance companies, does benefit the insured, and the society in some situations. For example, visiting doctors more often, resulting in higher than expected medical costs, is a moral hazard to the insurance company, but it may be beneficial to the insured and the society if the covered medical treatment is appropriately effective.

Manning, et al. (1987) showed that for poor adults who had high blood pressure at beginning of the experiment they studied, there was a clinically significant reduction in blood pressure for those in the free plan compared to those in the plans with cost sharing, and the magnitude of this reduction would lower mortality by about 10 percent each year among this group, about 6 percent of the whole population. An individual's health not only has a bearing on his or her well-being, but also on the value of his or her labor to the economy. There exist positive externalities in the provision of health care: that is the social 
benefit of providing health care to an individual often exceeds the private benefit ${ }^{2}$. Therefore, developing social insurance for health care may be an effective way to increase the supply of health care, and to improve the health level of the whole population, provided that benefits derived are provided in a cost-effective manner (designing such system is, of course, a challenging public choice problem).

Optimizing copayment rate of health care insurance is an important method to cope with mortal hazard. In the following, we will establish models to determine optimal copayment rate which minimizes social cost. Our method of optimizing copayment rate can help regulator constitute most effective policy to cope with moral hazard of health care insurance and benefit the insured and society as whole.

\section{RESEARCH METHODS}

Decision makers for health care policy must evaluate the benefit and loss resulting from any policies they implement. For example, for cost sharing policy of health care insurance, higher cost-sharing would decrease the cost due to the over consumption of health service, but it would, on the other hand, increase the financial risk to the insured (Meng, Jia and Yuan, 2011). The decision maker should find an optimal level of cost sharing by balancing the benefit and loss resulting from higher or lower cost sharing, and not only at individual level, but at the societal level as well. For those with lower risk of diseases, using higher cost sharing policy and limit the over consumption of health service may be a better choice (Figure 1), but for those with higher risk of diseases, it may be better to use lower cost sharing policy and encourage them to use some medical or preventive services by reducing their financial burden (Figure 2). Please note that both Figure 1 and Figure 2 are sketch figures which are only applied to convey basic meaning of optimal copayment ratio with different disease risks.

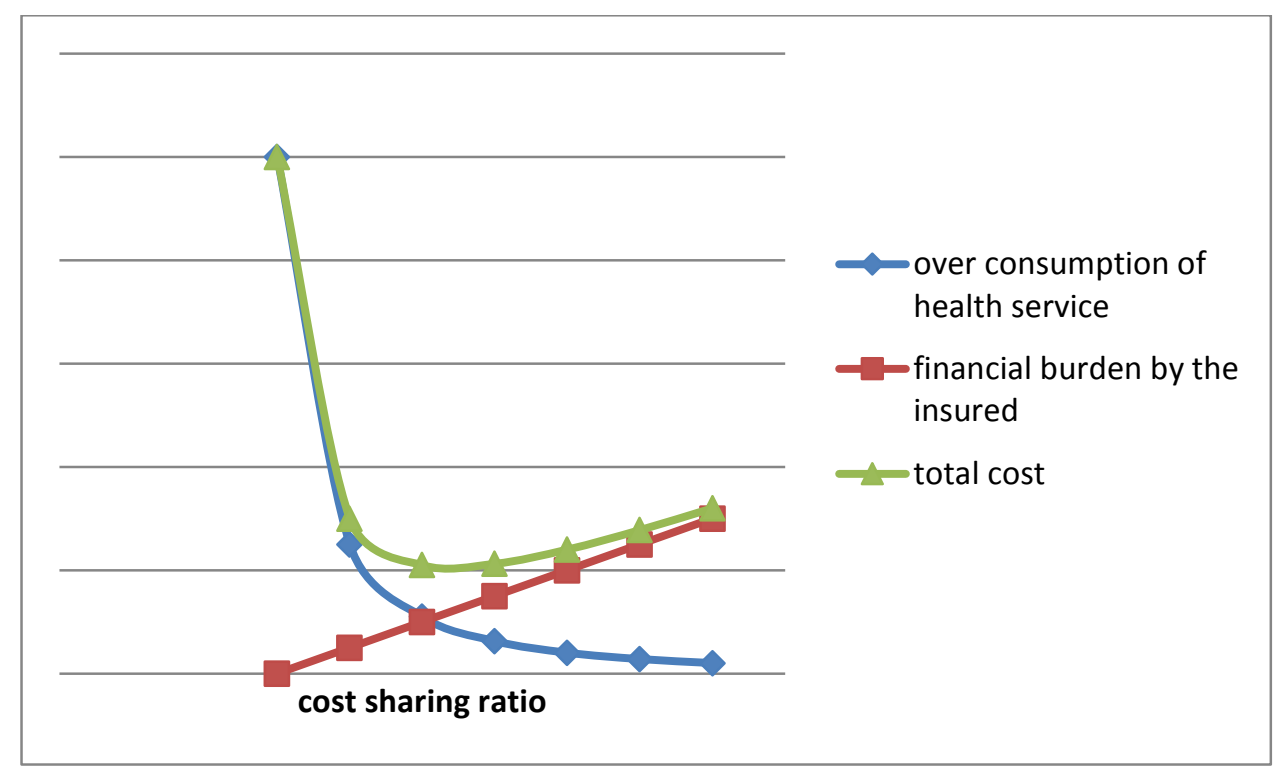

Figure 1. Optimal cost sharing ratio with lower risk diseases

\footnotetext{
${ }^{2}$ Please see the article titled "Why is there public provision of health care ?" http://www.parliament.uk/documents/commons/Scrutiny/SU\%20Economics\%20in\%20practice\%20$\% 20$ healthcare\%20(1).pdf
} 


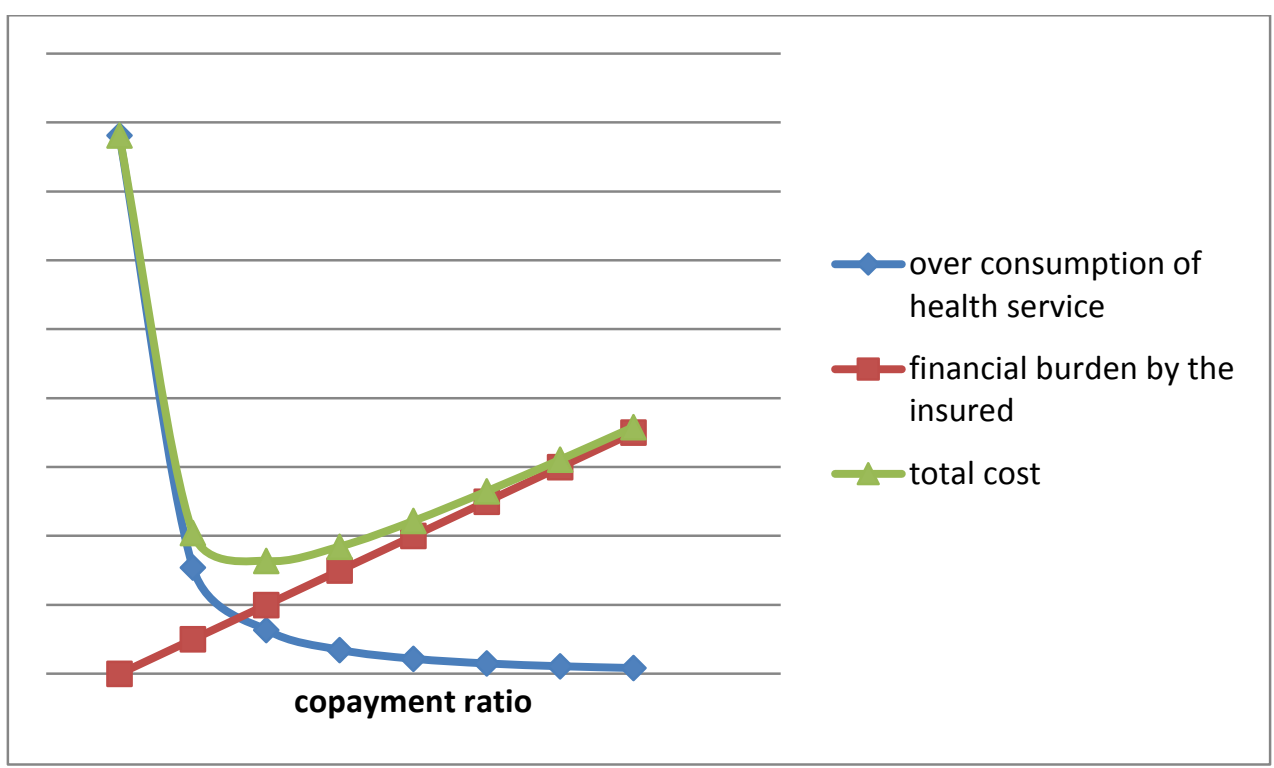

Figure 2. Optimal cost sharing ratio with higher risk diseases

An example of such a policy is the Social Health Insurance in China, in which the copayment rate for general illness is much higher than that for serious illness. But the values of copayment rate for the two sorts are different for different provinces. Here, we use Shanghai as an example to illustrate the difference of copayment rates for general illness and serious illness. For general illness, the copayment rate is between $30 \%$ to $50 \%$ for working population. For the person whose birth date is before 31-Dec-1955, between 1-Jan-1956 and 31-Dec-1965, and after 31-Dec-1965, the copayment ratio is $30 \%, 40 \%$, and $50 \%$ respectively. And for retired persons, the copayment ratio is between $20 \%$ to $30 \%$ depending on which class of hospitals the patient visits. The higher the class of the hospital, the higher the copayment ratio it is. However, for serious illness, e.g., cancers, uremia, serious mental diseases, the copayment rate is only $15 \%$ for persons whose age is less than retirement age, and for the retired population, it is only $8 \%$.

In the following, we will establish the models, carry out numerical analysis of determining optimal copayment for health care insurance and discuss the sensitivity of optimal copayment rate to the change of important parameters.

\section{Single payment of premium}

Let copayment ratio be $p$, medical cost of the insured for single payment be $C$, the total cost of health service be $C_{1}$ and the ratio of over consumption of health service be $\frac{k}{p}$, where $k$ is defined as the coefficient of over consumption of health service. Then, financial burden by the insured is $p C$, the over consumption of health device is $C_{1} k / p$ and total social cost will be:

$$
T C=p C+C_{1} k / p .
$$

The first and second order conditions are

$$
\begin{aligned}
& \frac{\partial T C}{\partial p}=C-\frac{C_{1} k}{p^{2}}=0 \\
& \frac{\partial^{2} T C}{\partial p^{2}}=\frac{2 C_{1} k}{p^{-3}}>0
\end{aligned}
$$


We find from equation (2) the optimal copayment ratio $p^{*}=\sqrt{\frac{C_{1} k}{C}}$.

In order to make sure $p \leq 1$, we let $\frac{C_{1}}{k} \leq C$, that is $k \geq \frac{C_{1}}{C}$. The optimal copayment ratio depends on the values of the medical cost of insured, the consumption of health service and the coefficient of over consumption of health service. We find from equation (4) that the higher the value of $C$, the lower the value of $C_{1} / k$, the lower the value of $p *$ it is, and vise versa. It means, on one hand, lower risk of health care, high class of health service and higher over consumption of health service is correspondence with higher copayment ratio (Figure 1 ), on the other hand, higher risk of health care, lower class of health service and lower over consumption of health service is correspondence with lower copayment ratio (Figure 2).

\section{level payment of insurance premium}

For level payment of insurance premium $A$ and for annual cost of health service $A_{1}$ and the coefficient of annual over consumption of health service $k_{1}$, we have

$$
T C=A(P / A, i, n) p+A_{1}(P / A, i, n) k_{1} / p,
$$

where $(P / A, i, n)$ is coefficient of present value of annuity, $i$ is discounting rate and $n$ is insurance term.

The first and second order conditions are

$$
\begin{aligned}
& \frac{\partial T C}{\partial p}=\left(A-\frac{A_{1} k}{p^{2}}\right)(P / A, i, n)=0 \\
& \frac{\partial^{2} T C}{\partial p^{2}}=\frac{2 A_{1} k}{p^{-3}}(P / A, i, n)>0
\end{aligned}
$$

We find from equation (6), the optimal copayment ratio $p^{*}=\sqrt{\frac{A_{1} k_{1}}{A}}$.

With consideration of annual growth of wage.

If we consider social health care insurance, it is necessary to take account of the annual growth of wage, we assume that the growth rate of wage (nominal wage growth, which includes both real wage growth and inflation) follows Vasicek $\mathrm{Model}^{3}$ as in equation (9):

$$
\frac{d W_{t}}{W_{t}}=d r_{w}=a_{w}\left(b_{w}-r_{w}\right) d t+\sigma_{w} d z_{w}
$$

We can obtain the expected values of annual growth rate of wage and the total wage at time $\mathrm{t}$ as:

$$
\begin{aligned}
E\left(r_{w}\right) & =e^{-a_{w} t}\left(r_{w}(0)+b_{w}\left(e^{a_{w} t}-1\right)\right) \\
E^{p}\left(W_{t}\right) & =W_{0} e^{E^{P}\left(\int_{0}^{t} r_{w}(u) d u / r_{w}(t)\right)} \\
& =W_{0}\left(e^{\left.E^{P}\left[\int_{0}^{t} r_{w}(u) d u\right)\right]+\frac{1}{2} \operatorname{var}\left[\int_{0}^{t} r_{w}(u) d u\right]}\right), \\
& =W_{0} e^{A_{t}+\frac{1}{2} B_{t}}
\end{aligned}
$$

\footnotetext{
${ }^{3}$ Equation (9) is similar to that in Pennacchi (1999).
} 


$$
\begin{aligned}
& A_{t}=E\left(\int_{0}^{t} r_{w}(u) d u\right)=\frac{r_{w 0}-b_{w}}{a_{w}}\left(1-e^{-a_{w} t}\right)+b_{w} t \\
& \text { and } B_{t}=\operatorname{Var}\left(\int_{0}^{t} r_{w}(u) d u\right)=\frac{\sigma_{w}^{2}}{2 a_{w}^{2}}\left(2 t-\frac{3-4 e^{-a_{w} t}+e^{-2 a_{w} t}}{a_{w}}\right)
\end{aligned}
$$

(For the proof, please see Mao (2018) and Mao and Wen 2021), where $E$ denotes the expected value.

We also assume that the premium rate of health care insurance is $v^{4}$ and the survival probability at time $t$ conditional the insured alive at age $x$ is ${ }_{t} p_{x}$.

Then the cost of health care insurance is $V F={ }_{t} p_{x} E^{P}\left(W_{t}\right) v$.

The total social cost of health insurance at time $t$ is

$$
T C(t)={ }_{t} p_{x}\left(E^{P}\left(W_{t}\right) v p+\frac{A_{1} k}{p}(F / A, i, t)\right),
$$

where $(F / A, i, t)$ is coefficient of future value of annuity.

The first and second order conditions are:

$$
\begin{aligned}
& \frac{\partial T C}{\partial p}={ }_{t} p_{x}\left(E^{P}\left(W_{t}\right) v-\frac{A_{1} k(F / A, i, t)}{p^{2}}\right)=0 \\
& \frac{\partial^{2} T C}{\partial p^{2}}=\frac{2 A_{1} k(F / A, i, t){ }_{t} p_{x}}{p^{3}}>0
\end{aligned}
$$

If ${ }_{t} p_{x} \neq 0$, we can obtain optimal copayment rate from equation (15) as

$$
p^{*}(t)=\sqrt{\frac{A_{1} k(F / P, i, t)}{E^{P}\left(W_{t}\right) v}},
$$

where $E^{P}\left(W_{t}\right)$ satisfies equation (11).

It is interesting to notice that the formula of optimal copayment rate has nothing to do with survival probability of the insured as long as it is not equal to zero.

\section{RESULTS AND DISCUSSION}

In the following, we will use social health care insurance as an example to illustrate its application and the sensitivity of optimal copayment rate $^{5}$ to the change of important parameters of consumption of health service, coefficient of over consumption of health service, premium rate, discounting rate and the time.

Table 1 lists the estimated value of parameters of wage equation and estimation errors using the data of China from 1980 to $2016^{6}$. According to the standard payment of health care of 2019, individual pays $2 \%$, individual's employer pays $7.5 \%$. the total premium rate is $9.5 \%$. the average deposit rate of three years is 0.0592 .

\footnotetext{
${ }^{4}$ Here the premium rate indicates the ratio of premium to the wage of the insured.

${ }^{5}$ Here copayment ratio indicates the ratio of coinsurance which is burden by the insured.

${ }^{6}$ The historical data of more long term in China has no continuity due to the great reform beginning at 1978 . Therefore, we use more recent data to fit Vasicek model.

${ }^{7}$ It is interesting to notice that the premium rate in China is very close to that of Canada, which in $10.03 \%$ in 2019 (Palacios and Barua, 2019).
} 
Table 1. Estimated parameters of wage equation and estimation error

(Please see Mao (2018)

\begin{tabular}{|l|l|l|}
\hline $\begin{array}{l}\text { MLE } \\
\text { China }\end{array}$ & $\begin{array}{l}\text { Growth } \\
\text { Rate of Wage }\end{array}$ & $\begin{array}{l}\text { Estimation } \\
\text { error }\end{array}$ \\
\hline estimation $\left(a_{w}\right)$ & 0.5780 & 0.2459 \\
\hline estimation $\left(b_{w}\right)$ & 0.1354 & 0.0101 \\
\hline estimation $\left(\sigma_{w}\right)$ & 0.0649 & 0.000553 \\
\hline \multicolumn{2}{|c|}{$r_{w}(0)=0.0820$} \\
\hline
\end{tabular}

Table 2 . Results of determining optimal copayment rate and the cost of Insurance $^{8}$

\begin{tabular}{|c|c|c|c|c|c|}
\hline \multicolumn{6}{|c|}{$\begin{array}{l}k=8, v=0.095, i=0.0592, r_{w}(0)=0.082, a_{w}=0.5780, b_{w}=0.1354, \sigma_{w}=0.0649 \\
A_{1}=4, W_{0}=61240, x=60\end{array}$} \\
\hline $\mathrm{t}$ & 1 & 2 & 3 & 4 & 5 \\
\hline$p^{*}$ & 0.0757 & 0.1097 & 0.1370 & 0.1607 & 0.1823 \\
\hline $\mathrm{VF}($ male $)$ & 5556.2 & 5408.2 & 5322.8 & 5272.5 & 5239.7 \\
\hline VF(female) & 5569.6 & 5435.5 & 5365.1 & 5329.9 & 5313.4 \\
\hline $\mathrm{t}$ & 6 & 7 & 8 & 9 & 10 \\
\hline$p^{*}$ & 0.2024 & 0.2214 & 0.2397 & 0.2575 & 0.2749 \\
\hline VF(male) & 5216.3 & 5195.8 & 5176.3 & 5155.0 & 5130.6 \\
\hline $\mathrm{VF}($ female $)$ & 5307.2 & 5305.6 & 5305.4 & 5305.4 & 5303.5 \\
\hline
\end{tabular}

Table 2 lists the optimal copayment rate and cost of health care insurance when time takes different values. Table 2 indicates that optimal copayment rate increases with the increase of time. Cost of health care insurance decreases with the time and the cost of health care insurance for female is greater than that of male due to the higher survival rate for female. Figure 1 through Figure 4 are our sensitivity analysis. Figure 1 through Figure 4 show that the copayment rate will increase with the increase of the consumption of health service, the increase of discounting rate, the increase of coefficient of over consumption. The sensitivity of optimal copayment on the change of parameter increases with the time. Especially, the optimal copayment is not sensitive to the change of discounting rate especially at earlier time. Our results also indicate that the copayment rate will decrease with the increase of premium rate, which means that copayment rate will decrease with the increase of the health risk of the insured. On the whole, finding optimal copayment rate by establishing model will help decision maker make most efficient and effective decision, optimize the resource of health care, limit over consumption of health service, minimize the social cost and the cost of the insured and reduce the health risk of the insured as possible as they can. Although some parameters are difficult to obtain, sensitivity analysis can help to estimate a change range of optimal solution so as the insured can control their risk and regulator of health care can control their cost in suitable ranges.

Moreover, it is very important to notice that optimal copayment rate greatly increases with time. We suggest that the regulator of health care insurance adjusts the copayment rate dynamically with time rather than keeps it constant.

\footnotetext{
${ }^{8}$ We use Chinese Life Table in 2013 to calculate the cost of health care insurance.
} 


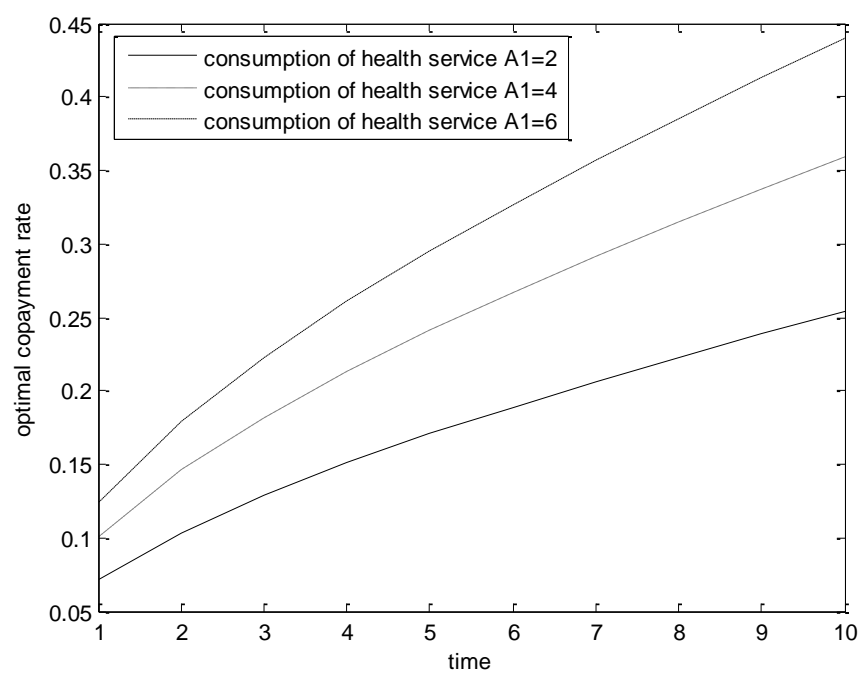

$k=8, v=0.08, i=0.05, r_{w}(0)=0.082, a_{w}=0.5780, b_{w}=0.1354, \sigma_{w}=0.0649$ $W_{0}=61240$

Figure 1. The change pattern of optimal copayment when the parameter of consumption of health service changes

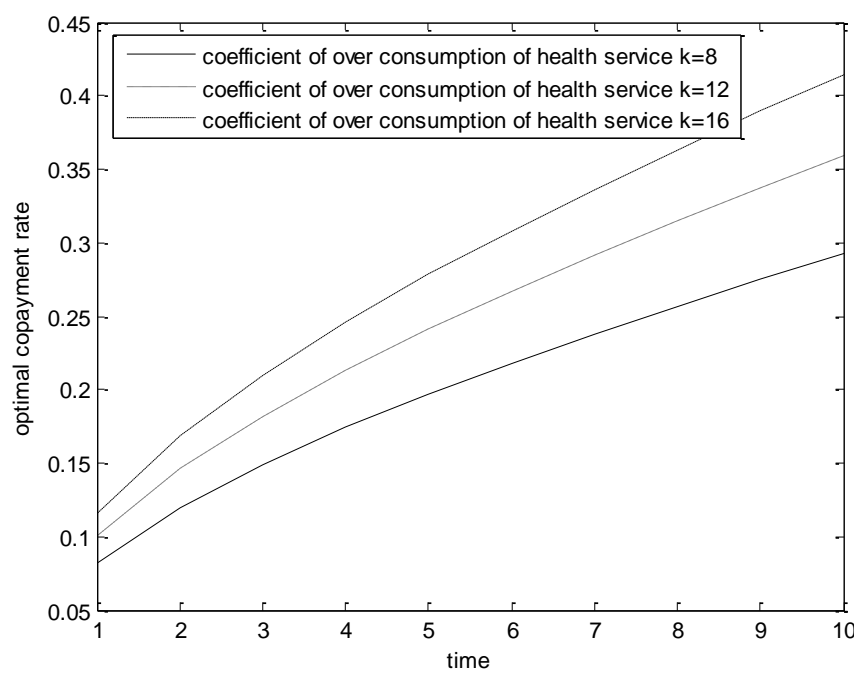

$A_{1}=4, v=0.08, i=0.05, r_{w}(0)=0.082, a_{w}=0.5780, b_{w}=0.1354, \sigma_{w}=0.0649$

$W_{0}=61240$

Figure 2. The change pattern of optimal copayment when the coefficnet of over consumption of health service changes 


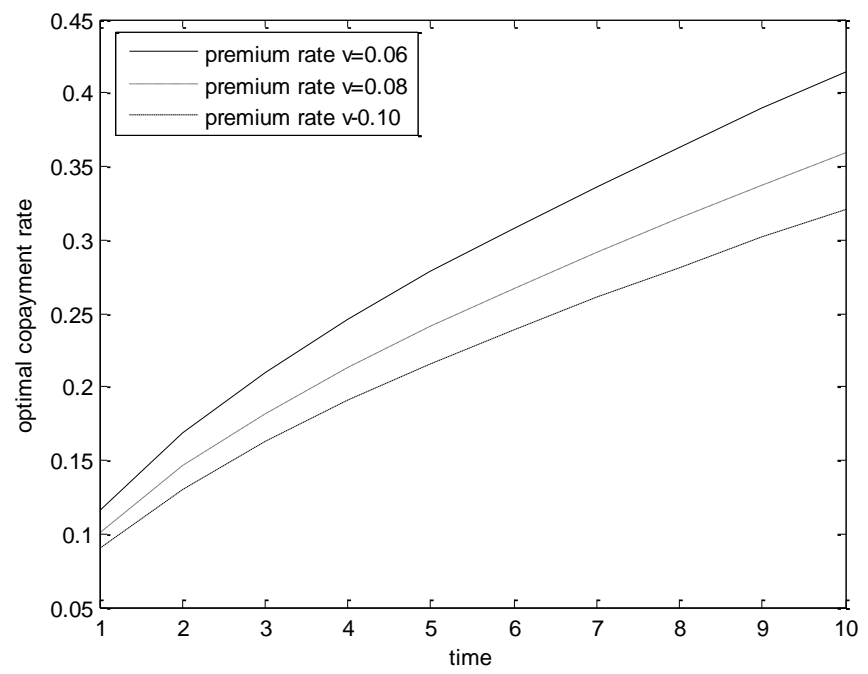

$$
\begin{aligned}
& k=8, A_{1}=4, i=0.05, r_{w}(0)=0.082, a_{w}=0.5780, b_{w}=0.1354, \sigma_{w}=0.0649 \\
& W_{0}=61240
\end{aligned}
$$

Figure 3. The change pattern of optimal copayment when the parameter of premium rate changes

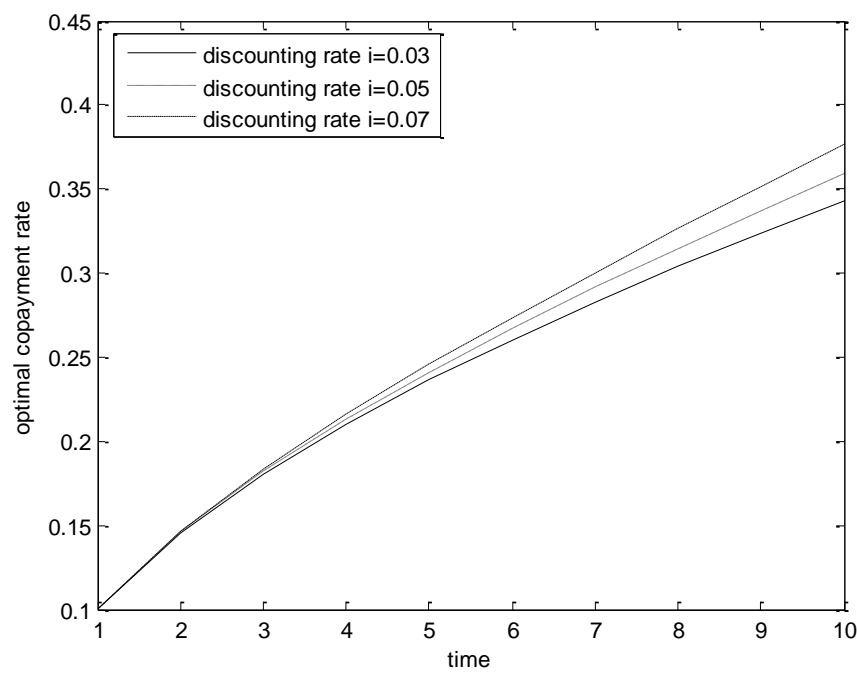

$$
\begin{aligned}
& k=8, v=0.08, A_{1}=4, r_{w}(0)=0.082, a_{w}=0.5780, b_{w}=0.1354, \sigma_{w}=0.0649 \\
& W_{0}=61240
\end{aligned}
$$

Figure 4. The change pattern of optimal copayment when the discounting rate changes

Figure 5 display the relationship among copayment rate, time and total social cost. The curve surface in Figure 5 is concave. Optimal copayment rate is correspondence with lowest total social cost. We find from Figure 5 optimal copayment rate increases with the increase of total social cost and total social cost increases with the 
increase of the time. Figure 6 displays the relationship between copayment rate and total social cost with time $t=2$. The curve with dash line is with parameters values of $k=16, v=0.04, A_{1}=6, i=0.05, W_{0}=61240$, the curve with solid line is with parameter values of $k=8, v=0.08, A_{1}=4, i=0.05, W_{0}=61240$ and the curve with dash-dot-line is with the parameters of $k=16, v=0.08, A_{1}=6, i=0.05, W_{0}=61240$. For other parameters please see Table 1. Figure 6 indicates that over consumption, higher consumption of health service and higher risk of the insured will lead to lower optimal copayment rate and vise verse.

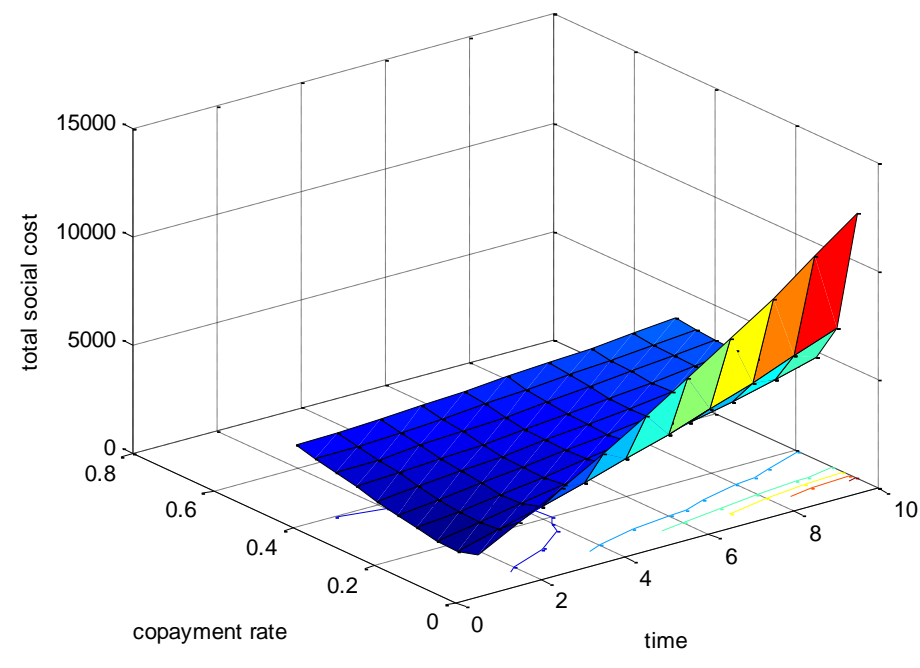

$$
\begin{aligned}
& k=8, v=0.08, i=0.05, r_{w}(0)=0.082, a_{w}=0.5780, b_{w}=0.1354, \sigma_{w}=0.0649 \\
& A_{1}=4, W_{0}=61240
\end{aligned}
$$

Figure 5. The relationship among total social cost, copayment rate and the time

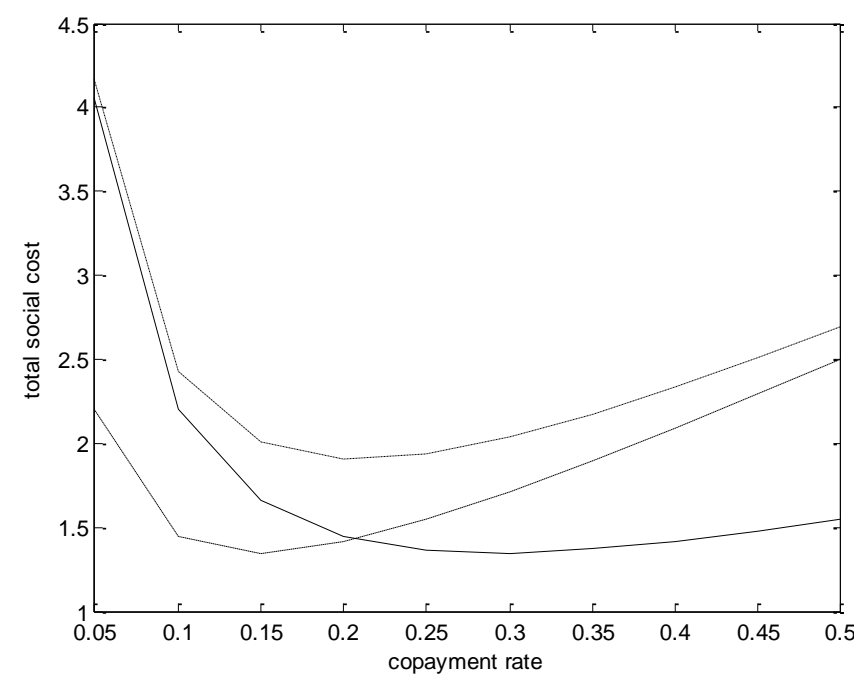

$$
i=0.05, r_{w}(0)=0.082, a_{w}=0.5780, b_{w}=0.1354, \sigma_{w}=0.0649, W_{0}=61240
$$

Figure 6. The change pattern of total social cost when copayment rate changes $(t=2)$ 


\section{CONCLUSION}

In this article, we discuss how the moral hazard affects health care insurance, the insured benefit and social cost. We also discuss how moral hazard affects copayment rate and how to determine optimal copayment ratio which benefits both the insured and society as whole. Finally, we carry out sensitivity analysis to illustrate the effect of the change of important parameters on optimal copayment rate.

\section{REFERENCES}

Life Table of China, (2013).

Manning, W. and J. Newhouse. (1987). Health insurance and the demand for medical care: evidence from a randomized experiment". America Economic Review, 77: 252-277.

Mao, H. , J. M. Carson and K. M. Ostazewski. (2018). Is Risk Taking or Moral Hazard Beneficial To the Insured and the Society? Working paper

Mao, H. (2018). Dynamic valuation of wrongful death compensation when the growth rate of the wage follows Vasicek model, Journal of Applied Quantitative Methods, 13:18-32.

Mao, H and Z. Wen. (2021). Optimal Replacement and Investment Strategy in A Defined Benefit Pension Plan with Cyclically Changing Economic Environment, Journal of Insurance Issues, Forthcoming.

Meng,Q., L. Jia and B. Yuan. (2011). Cost-sharing mechanisms in health insurance schemes: A systematic review, working paper, http://www.who.int/alliancehpsr/projects/alliancehpsr_chinasystematicreviewcostsharing.pdf

Nyman, J. A. (1999). The value of health insurance: The access motive, Journal of Health Economics, 18:141-152.

Nyman, J. A. (2004). Is " Moral hazard" inefficient? The policy implications of a new theory, Health Affairs, 23:194-199.

Palacios, M and B. Barus. (2019). The price of public healthcare 2019, Fraser Research Bulletin, August, 1-10.

Pauly, M.V. (1983). More on moral hazard, Journal of Health Economics, 2: 81-85.

Pennacchi, G.G. (1999). The value of guarantees on pension fund returns, The Journal of Risk and Insurance, 66, 219-237.

Shahar, O.B. and K.D. Logue. (2012). Outsourcing regulation: How insurance reduces moral hazard, Michigan Law Review, 111:197-248.

Vasicek, OA. (1977). An Equilibrium Characterization of the Term Structure, Journal of Financial Economics 5, 177-188. 